\title{
Do Socially Conscious ETFs Match Their Active Counterparts?
}

\author{
Ryan Cultice ${ }^{1} \&$ Steven Dolvin ${ }^{2}$ \\ ${ }^{1}$ Honors Student, Lacy School of Business, Butler University, Indianapolis, United States \\ ${ }^{2}$ Professor, Lacy School of Business, Butler University, Indianapolis, United States \\ Correspondence: Steven Dolvin, Lacy School of Business, Butler University, Indianapolis, IN 46208, United \\ States.
}

Received: March 4, 2020

doi:10.5539/ibr.v13n4p100
Accepted: March 23, $2020 \quad$ Online Published: xx, 2020

URL: https://doi.org/10.5539/ibr.v13n4p100

\begin{abstract}
Over the past decade, Socially Responsible Investing (SRI) has grown at a rapid pace and, by some estimates, now represents a quarter of the $\$ 48$ trillion in assets under professional management in the United States. At the same time, investors have broadly shifted from active to passive investing strategies. While there is significant research in each of these respective areas, we believe that we are the first to examine whether a socially conscious investor can employ a passive approach or if the constrained nature of SRI necessitates active management. As such, we examine the performance of socially conscious ETFs versus a matched sample of actively managed SRI mutual funds. We find the performance, as a whole, to be insignificantly different between the two groups, suggesting that the benefits of active management in this construct effectively offset the cost advantage of passive ETFs.
\end{abstract}

Keywords: socially responsible investing, ESG, actively managed mutual funds, exchange traded funds

\section{Introduction}

"Once a fringe concept, environmental, social-and governance-(ESG) based investing has hit the mainstream."

\section{Matt Wirz (2018), The Wall Street Journal}

Over time, the concept of corporate social responsibility (CSR) has evolved to include environmental, social, and governance (ESG) scores as a cornerstone for evaluating securities in the context of a socially responsible investing (SRI) framework. Today, more than ever, individual and institutional investors are increasingly interested in using SRI-focused metrics as part of their investment decision making processes. Previous studies have noted that a corporation's commitment to strong CSR and ESG ratings can result in a lower cost of debt, a lower cost of equity, and potentially better corporate financial performance. Additionally, prior studies have concluded that an individual investor is not penalized, in terms of investment performance, for following a philosophical investment approach that targets ESG-constrained companies or funds.

At the same time, the investment industry has seen money moving rapidly out of actively managed funds and into passively managed funds, which is primarily attributed to passively managed funds generally outperforming their actively managed counterparts over the long-run due to lower expenses. However, current research surrounding the underperformance of actively managed funds has primarily been focused on the performance of active managers relative to broad consolidated indexes, rather than on constrained investment approaches, such as characterizes SRI. In particular, an SRI approach relies on screening ESG data and limiting the investments available for purchase. Thus, the question becomes whether passive management is able to sustain its performance advantage when subject to such a constraint. Therefore, the purpose of this study is to examine the performance of passively managed ESG-based exchange traded funds (ETFs) relative to a matched sample of their actively managed counterparts. Stated differently, we consider whether the constrained SRI investment approach is possible through passively managed ETF's or, if by the nature of this niche market, the approach necessitates active management.

To explore this issue, we create a matched sample of ESG-focused ETFs and related actively managed ESG mutual funds. While the number of such ETFs is growing rapidly, there are very few funds with sufficient data available. For example, we require funds to have at least one year of return data available, reasonable trading 
volume, and a stated sustainability mandate. As such, our sample is limited to 28 passively managed ETFs. We understand that the small sample may reduce the significance and reach of our findings, but we believe our contributions are meaningful given the infancy of this area and the increasing focus on it.

As expected, in a univariate setting we find that the ETFs have lower expense ratios than their actively managed counterparts. We also find, however, that the ESG-focused ETFs have returns (absolute and risk-adjusted) that are insignificantly different from the actively managed mutual funds. Moreover, when we apply a multivariate framework, we find that there continues to be no difference in risk level or performance between the passive ESG ETFs and their actively managed mutual fund counterparts.

These findings have meaningful implications. First, we conclude that socially conscious investors have the same choice as more traditional investors - i.e., they are able to choose low-cost ETFs to employ their investment strategy. Second, however, we note that the typical outperformance we see with passive management is non-existent, at least in our initial sample. Thus, employing SRI practices does seem to benefit, at least to some extent, from active management. Taken together, our findings suggest that SRI investors could follow either an active or passive approach and expect to earn similar risk-adjusted returns, with the apparent cost advantage of the ETFs offsetting the active benefit within the SRI investment structure.

\section{Background and Literature Review}

\subsection{Corporate Social Responsibility}

The modern concept of Corporate Social Responsibility (CSR) has evolved extensively since the countervailing framework developed by Milton Friedman. Friedman (1970) argued that only people themselves can have responsibilities, whereas corporations act as artificial people and therefore cannot have responsibilities. According to Freidman (1970), an employee of a corporation has a responsibility to their employer, and this responsibility is to "make as much money as possible while conforming to the basic rules of society." Although the employee may have other moral obligations, or social responsibilities, Friedman (1970) argues that when pursuing these, the employee is acting as a principal, not an agent, as the employee is spending their own time and money in pursuit of such social responsibilities. Freidman (1970) therefore concludes that "there is one and only one social responsibility of business - to use its resources and engage in activities designed to increase its profits so long as it stays within the rules of the game."

Despite Friedman's view, the modern concept of CSR has gained much traction over the past few decades due to national crises and scandals, such as Watergate and the Vietnam War (Epstein, 1989). Howard Bowen (1953), known as the father of CSR, first defined CSR as "the obligations of businessmen to pursue those policies, to make those decisions, or to follow those lines of action which are desirable in terms of the objectives and values of our society." In its infancy stage, CSR mainly revolved around corporate resources being used to pursue social ends, corporate philanthropy, and volunteerism, but as CSR gained traction its definition has been modified over the decades to include the concept of "the triple bottom line," which is the goal of creating social, environmental, and financial benefits (Fulton, Kahn \& Sharples, 2013),

As the notion of CSR became more popular, Freeman and McVea (2000) advanced the idea that the owners of a corporation expanded to more than those with just a financial stake in the company. Freeman and McVea argue that to better ensure long-term sustainability, managers of a corporation must consider actions in terms of many different groups, such as the government, the community and employees. Following these principles, shareholders began demanding additional transparency regarding corporate performance that goes beyond traditional financial measures.

As the concept of CSR has evolved into a more modern definition, CSR has begun to formally adopt measures of environmental, social and governance (ESG) qualities. Or, in the words of Fulton, Kahn and Sharples (2013), it is "evident that CSR has essentially evolved into ESG." Although mandates for reporting ESG scores in annual reports are not required legally, many corporations are beginning to report this information voluntarily. Consistent with this view, in their Survey of Corporate Responsibility Reporting, KPMG (2017) found that 93\% of the world's largest 250 companies are reporting CSR statistics and measures in their annual reports, compared to only 35\% reporting CSR measures in 1999. Moreover, the Governance \& Accountability Institute (2018) reports that $85 \%$ of the companies in the S\&P 500 published Corporate Responsibility Reports in 2017, compared to only $20 \%$ in 2011.

With such an emerging interest in CSR/ESG reporting, many studies have examined the link between CSR and the corporate cost of capital. For example, Goss and Roberts (2011) find that corporations with CSR "concerns" pay between 7 and 18 basis points more on loan spreads as compared to those corporations with a strong 
commitment to CSR. In addition, Clark and Viehs (2014) report that corporations with higher CSR quality are subject to higher bond ratings because lenders view a commitment to CSR as an effective risk mitigation tool. From an equity standpoint, Ghoul, Guedhami, Kwok, and Mishra (2011) examine the link between CSR and equity financing and find that "firms demonstrating stronger CSR scores find cheaper equity financing, as their adherence to socially responsible practices improves company valuation and diminishes risk." From a broader standpoint, these findings do not appear to be unique. In particular, in a comprehensive report that aggregated 19 different studies, Fulton, Kahn and Sharples (2013) find that in 100\% of the cases examined, corporations with higher CSR quality had a lower cost of capital in terms of both debt and equity financing.

From an investment perspective, the most important question to answer is whether enhanced CSR results in improved corporate financial performance (CFP). All else equal, the lower cost of capital should increase equity values. However, if firms avoid profit generating activities or if CSR is more costly, then net returns might be lower. Given the competing influences, it is not surprising that many studies have produced mixed results.

With the relative newness of CSR in general, much of the disparity in results, however, may be related to inconsistent working definitions of what CSR (and ESG) actually entail. Despite this, in a report that aggregated findings from over 2,000 studies, Friede, Busch and Bassen (2015) stated that "the results show that the business case for ESG investing is empirically very well founded. Roughly $90 \%$ of the studies find a nonnegative ESG-CFP relation." In addition, Orlitzky, Schmidt and Rynes (2003) suggest that studies that concluded CSR either has a negative, or no impact on CFP, had errors in CSR definitions. With all this in mind, it is not surprising that the definitions of CSR/ESG/SRI continue to evolve.

\subsection{A Brief History of Socially Responsible Investing}

The UK Investment Forum describes socially responsible investing (SRI) as "investments enabling investors to combine financial objectives with their social values" (see Munoz-Torres, Fernandez-Izquierdo, \& Balaguer-Franch, 2004). While CSR encourages corporations to pursue desirable societal goals and outcomes, SRI allows individual investors to invest money in funds that align with their societal goals. Similar to the evolution of CSR, SRI was not initiated by Wall Street analysts, but rather, Schueth (2003) notes that the movement was primarily consumer-driven. Moreover, Fulton, Kahn and Sharples (2013) suggest that, in a sense, CSR is the corporate form of, or response to, SRI.

The origins of SRI date back to ancient biblical times where Jewish law instructed followers how to invest ethically. In fact, over 300 years ago, John Wesley, the founder of Methodism, stated that the second most important subject in the New Testament was how to use money. For centuries, those whose religious traditions included nonviolence have generally embraced SRI. In these cases, the earliest history of SRI typically followed an exclusionary approach, i.e., "thou shalt not support sinful practices." This approach has manifested itself in funds that avoid investing in so-called "sin stocks," or those companies that make alcohol, tobacco or gambling products.

Similar to how CSR gained traction out of national crises and scandals, the modern concepts of SRI gained popularity in the 1960s as the Vietnam War, Watergate, Civil Rights movement and concerns over equality were ripping through the US (Schueth, 2003). As the Vietnam War became more unpopular, people began looking for ways to boycott this cause within their investment portfolios. Around 1970, people identified Agent Orange, a toxin sprayed over Vietnam during the war, as a controversial weapon. Investors then began pulling money from Dow Chemical, the maker of Agent Orange. The national crisis of the Vietnam War proved to be the main catalyst for the increased attention and popularity of SRI (Townsend, 2017).

By the 1990's interest in SRI had increased significantly, resulting in a growing number of related investment products. In fact, the SRI approach had gained so much popularity that an index was created to measure general SRI performance. Specifically, the Domini Social Index was created to track the performance of 400 large capitalization U.S. Corporations that were considered to be the most socially responsible based on a prescribed set of social and environmental criteria.

Until recently, however, SRI investing has lacked a formal definition. As such, as more investors have migrated into this area, there has been an increased focus on providing objective measures for determining funds and companies that are socially responsible. As a result, the industry has begun to adopt ESG (i.e., environmental, social and governance) scores as the primary tool for gauging a company's, or fund's, level of social responsibility. While SRI provides a broad framework for defining ethical investing, ESG scores provide objective factors and data to actually implement an SRI philosophy. The notion of SRI has been around for centuries, while ESG factors have been advanced throughout the past decade as different governing bodies, such as the UN Principles for Responsible Investment, have begun to collect and report more ESG data. 
As a first step in ESG scoring, the chart below from The Forum for Sustainable and Responsible Investment (USSIF, 2017) shows common characteristics of ESG funds. ESG data includes environmental data (such as carbon emissions), social data (such as employee diversity), and governance data (such as anticorruption statistics).

\begin{tabular}{|c|c|c|}
\hline Environmental & Social & Governance \\
\hline $\begin{array}{ll}\text { - } & \text { Water use and conservation } \\
\text { - } & \text { Sustainable natural } \\
\text { - } & \text { resources/agriculture } \\
\text { - } & \text { Pollution/toxins } \\
\text { - } & \text { Climate chnology } \\
\text { - } & \text { Green building/smart growth }\end{array}$ & $\begin{array}{ll}\text { - } & \text { Workplace safety } \\
\text { - } & \text { Labor relations } \\
\text { - } & \text { Workplace benefits } \\
\text { - } & \text { Diversity and anti-bias issues } \\
\text { - } & \text { Avoidance of tobacco and } \\
& \text { other harmful products } \\
\text { - } & \text { Human rights } \\
\end{array}$ & $\begin{array}{ll}\text { - } & \text { Corporate political } \\
& \text { contributions } \\
\text { - } & \text { Executive compensation } \\
\text { - } & \text { Board diversity } \\
\text { - } & \text { Anti-corruption policies } \\
\text { - } & \text { Board independence }\end{array}$ \\
\hline
\end{tabular}

In the past two decades, there has been substantial growth in the number of companies that report statistics regarding underlying ESG practices, as well as those who collect and analyze it. For example, according to Amel-Zaded and Serafeim (2018), thirty years ago fewer than 20 companies reported ESG data, whereas in 2016, over 9,000 companies reported ESG data. Perhaps due to increased ESG reporting and collection, recent statistics from JP Morgan (2018) show that SRI is moving more mainstream every year. As of April 2018, JP Morgan estimated that globally there is almost \$23 trillion of estimated SRI assets under management (AUM).

The USSIF (2018) found that SRI assets in the US have a compounded annual growth rate of almost $14 \%$ since statistics on SRI investment began in 1995. With increased data availability and investor interest, USSIF (2018) found that assets of funds that focus on sustainable investing have grown over 38\% since 2016. Overall, assets invested in SRI-related products in the U.S. total approximately $\$ 12$ trillion, which is about $25 \%$ of the $\$ 48$ trillion under professional management in the U.S. The growth highlighted by these changes illustrates the increasing interest in SRI investing.

Of the almost $\$ 12$ trillion of SRI AUM in the United States, roughly $64 \%$ is managed through undisclosed investment vehicles, which shows the limited nature of voluntary disclosures amongst those incorporating ESG criteria. Registered investment companies make up 22\% of the total SRI AUM in the US. There are over 600 mutual funds that promise to include ESG screening when selecting investments, with almost \$2.6 trillion of AU. This compares to ESG ETFs having only \$7B of AUM, which illustrates the newness of this specific area.

Despite the significant disparity between the AUM of ESG mutual funds compared to ESG ETFs in the US, JP Morgan (2018) found that the popularity of ESG ETFs has been surging since 2016. In fact, between 2016 and 2017, there were 22 ESG focused ETFs launched in the US alone, accounting for $10 \%$ of all new funds launched over that time. As of April 2018, there were over 100 ESG-focused ETFs that accounted for \$11 billion globally. This surge in popularity adds to the importance of conducting research in this area.

\subsection{Environmental, Social and Governance (ESG) Fund Performance}

With the significant increase in SRI investing, as evidenced by the large amount of fund flows into this area, the standing question became whether following an SRI approach required sacrificing investment return. To answer this question, Dolvin, Fulkerson and Krukover (2019) examine if there is any penalty in terms of return for investors who followed this philosophical approach compared to those investors that did not. They find that funds with high sustainability scores as rated by Morningstar have about the same risk adjusted return as compared to other funds. This suggests that investors of ESG funds do not sacrifice return by following their philosophical approach to investing.

Although there is not much difference in risk-adjusted returns between ESG funds and other funds, Dolvin, Fulkerson, Krukover (2019) find that there is a difference in risk profile since ESG funds are primarily concentrated in large cap stocks, which leads to a potential sacrifice in diversity of the overall portfolio. Other studies (e.g., O'Brien, Liao \& Campagna, 2017), however, find that although an SRI approach does come with a limited range of investment opportunities, it does not come with additional risk as their sample yielded similar Sharpe ratios and standard deviations for both the SRI indexes and their broad market counterparts. Additionally, Morgan Stanley (2015) found that SRI mutual funds had equal or higher returns, and equal or lower volatility when compared to traditional mutual funds. Taken as a whole, these results, at a minimum, suggest that social investors are able to follow their preferred philosophy without sacrificing investment return. 


\subsection{Active vs. Passive Management}

In modern investments, investors must make a broad choice: active vs. passive investing. At the fund level, those who choose to be active investors generally resort to mutual funds. Such active management generally comes with higher expenses, particularly when compared to passive counterparts. Whether or not the higher fee paid to the active manager results in better performance is the framework for the active versus passive debate. Investors who prefer a passive approach can choose a passively managed mutual fund or an exchange traded fund (ETF) that tracks a specific index.

There has been much debate over which investment style provides the best return: actively managed mutual funds or passively managed ETFs. Advocates of actively managed mutual funds argue that rigorous research, sophisticated portfolio construction, and the personal touch of a portfolio manager leads to picking stocks that can outperform indexes. On the other hand, advocates of passively managed indexes and ETFs argue that it is very difficult to beat the market, and, instead, this approach tries to match the return of the overall market, at a much lower cost. After the high fees that come along with active management, advocates of passive management argue that returns should be similar between the two approaches (if not better for passive funds). Essentially, active management believes that markets are not always perfect and, by identifying market inefficiencies, it is possible to select stocks to beat the market. Passive management, however, is rooted in the efficient market hypothesis and relies on the fact that it is very difficult to consistently beat the market.

Although there has been an ongoing argument over which management style performs the best, there has been a noticeable change in fund flows out of actively managed styles and into passively managed styles. Since their introduction in 1993, the Investment Company Institute (ICI Global, 2018) reports that assets in ETFs have grown to over $\$ 4.3$ trillion as of mid-2018. As a whole, in 2016, Petruno (2017) notes that passively managed funds accounted for 42 percent of the total money invested in the U.S. stock market. In fact, Stein (2018) reports that market experts predict passive investments to overtake active funds in proportion by the end of 2019 .

With this question at hand, extensive research has been conducted analyzing whether an actively managed portfolio provides more value than a passively managed portfolio, especially given the greater expense ratios that come along with actively managed funds. Specifically, Prondzinski (2010) analyzed the performance of different types of actively managed mutual funds compared to passive counterparts over 1995-2008 to see which management style resulted in better performance. To measure performance, Prondzinski (2010) used the Sharpe ratio, which is the average return the fund earned in excess of the risk-free rate, scaled by its standard deviation. Prondzinski (2010) concluded that the Sharpe ratio was significantly greater for actively managed funds in $16 \%$ of the tests, while the Sharpe ratio was significantly greater for passively managed funds $84 \%$ of the time.

Prondzinski (2010) segmented the results where the Sharpe ratio was greater for actively managed funds and found the only time this occurred was when the funds were mid-cap blends, small-cap blends, or small-cap value funds. Prodzinski (2010) further separated these results into time segments that reflected bull and bear markets and found no correlation between market performance and which management style performed better. These results suggest that passively managed large cap funds outperformed their passive counterparts in all tests Prondzinski completed from 1995-2008. These findings are important considering that many ESG funds have a large-cap focus. Overall, Prondzinski (2010) concluded that, in the long-run, passive management resulted in better performance than active management, suggesting that the higher fees associated with active management do not generate additional value for investors.

\section{Contribution}

Based on existing research, we can make four primary conclusions. First, SRI is becoming more mainstream and attracting more attention as the fund flows into SRI-based funds are increasing rapidly. Second, the growing collection of ESG data has provided investors an increasingly objective way to evaluate SRI investments. Third, passive investing has become more prevalent due to an increased awareness of the impact of higher fees on net returns. Fourth, ESG-focused ETFs are surging in popularity (and number) and are attracting new fund flows. The unknown issue, however, is whether the passive ETF structure is capable of retaining its performance advantage in a constrained (i.e., ESG) investment framework. Meaning, if I as an investor wish to undertake an SRI approach, does this, by its restrictive nature, necessitate active investing, or can passive ETF index funds provide the same investment philosophy with lower costs and equivalent (or even higher) returns? That is the question we aim to answer.

If we find that passively managed ESG ETFs perform just as well as (or better than) their active counterparts, then we may conclude that SRI investors can choose passive ESG-focused ETFs to implement their investment philosophy without losing any perceived benefits of active management. If we find that our passive sample 
underperforms, then we may suggest that SRI investing may not be suitable for passive investment products, which would be counter to more traditional broad-based investment strategies.

\section{Research Methodology and Data}

\subsection{Matched Sample}

To begin the data collection process, we consolidate data from Morningstar, the U.S. Forum for Sustainable Investing, and CBOE Global Markets. To be included in the sample, we require three things: (1) that the fund actually has a stated SRI mandate, (2) that each fund has at least one year of return history to provide for a meaningful analysis, and (3) the fund has average daily trading volume above 200 shares. As a result, our final sample contains only 28 ESG-focused passively-managed ETFs. Although our sample size is quite small for typical finance area research, this number is reflective of the newness of this particular segment of the market, so we believe any preliminary results can still provide a meaningful contribution.

To match each of the respective ESG ETFs with an actively managed ESG mutual fund, we consulted the USSIF database, which provides a list of mutual funds that have a specific sustainability mandate. Additionally, a separate search in Morningstar returned another list of mutual funds that had a specific sustainability mandate. These searches resulted in 216 unique mutual funds with a sustainability mandate from which to match the ETFs. Our primary matching criteria is fund strategy (e.g., Consolidated ESG, Environmental or Social). Next, we matched the focus of the fund (e.g., World, US, International or Emerging Markets). Then we selected the mutual fund that had the closest possible style map (i.e. large-cap value, large-cap blend, large-cap growth, etc.) to the ETF. The final matching criterion was based on fund size, as measured by assets under management (AUM). Table 1 lists the final matched sample. When matching environmental ETFs to mutual funds, for example, preference was given to the sub-focus of the fund (e.g., fossil fuel free ETFs matched with a fossil fuel free mutual fund). Since our search resulted in a limited number of mutual funds that shared the same sub-focus of some ETFs, the same mutual fund was occasionally chosen as the matched fund, assuming the focus and style maps of the funds were also comparable.

Table 1. Matched Sample

\begin{tabular}{|c|c|c|c|}
\hline \multicolumn{2}{|c|}{ Passive ETFs } & \multicolumn{2}{|c|}{ Active Mutual Funds } \\
\hline Ticker & Name & Ticker & Name \\
\hline \multicolumn{4}{|c|}{ Consolidated ESG Funds } \\
\hline ESGE & iShares MSCI EM ESG Optimized & SEMVX & Hartford Schroders EM Eq A \\
\hline NUEM & Nuveen ESG Emerging Markets Eq ETF & MMKBX & Morgan Stanley Inst Emerging Mkts A \\
\hline ESGN & Columbia Sustainable Intl Eq Inc & DOMAX & Domini Impact Intl Eq A \\
\hline ESGD & iShares MSCI EAGE ESG Optimized & NIEAX & Dreyfus/Newton International Equity A \\
\hline NUDM & Nuveen ESG Intl Dev Mkts Eq ETF & TSOHX & TIAA-CREF Social Choice Intl Eq Advisor \\
\hline DSI & iShares MSCI KLD 400 Social & NWFAX & Nationwide A \\
\hline KRMA & Global X Conscious Companies & BIRIX & BlackRock Impact US Equity Instl \\
\hline ESGS & Columbia Sustainable US Equity Inc & ARFFX & Ariel Focus Investor \\
\hline ESGU & iShares MSCI USA ESG Optimized ETF & WSEFX & Walden Equity \\
\hline SUSA & iShares MSCI USA ESG Select ETF & MUIFX & Nationwide Institutional Service \\
\hline ESG & FlexShares STOXX U.S. ESG Impact & JICAX & JPMorgan Intrepid Sustainable Equity \\
\hline NUMG & Nuveen ESG Mid-Cap Growth ETF & ADJEX & Azzad EThical \\
\hline NULV & Nuveen ESG Large-Cap Value ETF & ARFFX & Ariel Focus Investor \\
\hline NULG & Nuveen ESG Large-Cap Growth ETF & BAFWX & Brown Advisory Sustainable Growth Instl \\
\hline NUMV & Nuveen ESG Mid-Cap Value ETF & MXOAX & Great-West Ariel Mid Cap Value Instl \\
\hline NUSC & Nuveen ESG Small-Cap ETF & WASOX & Walden Small Cap Fund \\
\hline ESGF & Oppenheimer Global ESG Revenue ETF & DEQAX & Dreyfus Global Equity Income Class A \\
\hline ORG & The Organics ETF & HGXAX & Hartford Global Impact A \\
\hline ESGG & FlexShares STOXX Glbl ESG Impact & GGEAX & Nationwide Global Sust Eq A \\
\hline ESGW & Columbia Sustainable Global Eq Inc & TPYAX & iShares Touchstone Premium Yield Eq \\
\hline \multicolumn{4}{|c|}{ Environmental Funds } \\
\hline SPYX & SPDR S\&P 500 Fossil Fuel Rsrv Free & TCCHX & TIAA-CREF Social Choice LwCrbn Eq \\
\hline CHGX & Change Finance US LgCp Fossil Fuel Fr & TCCHX & TIAA-CREF Social Choice LwCbrn Eq \\
\hline LOWC & MSCI ACWI Low Carbon Target ETF & PORIX & Trillium P21 Global Equity Instl \\
\hline CRBN & iShares MSCI ACWI LwCrbn Target ETF & PORIX & Trillium P21 Global Equity Instl \\
\hline
\end{tabular}




\begin{tabular}{|c|c|c|c|}
\hline EFAX & SPDR MSCI EAFE Fossil Fuel Free ETF & GCINX & Green Century MSCI Intl Indx Indvl Inv \\
\hline EEMX & SPDR MSCI Em Mkts Foss Fuel Free ETF & DESIX & Em Mkts Sustainability Core 1 Portfolio \\
\hline ICLN & iShares Global Clean Energy ETF & NALFX & New Alternatives A \\
\hline PBD & Global Clean Energy ETF & NALFX & New Alternatives A \\
\hline PBW & WilderHill Clean Energy ETF & ALTEX & Firsthand Alternative Nergy \\
\hline QCLN & NASDAQ Clean Edge Energy Fund & FSLEX & Fidelity Select Envir and Alt Engy Port \\
\hline FAN & ISE Global Wind Energy Index Fund & HEOMX & Hartford Environmental Opportunities A \\
\hline TBLU & Tortoise Global Water ESG & AWTAX & AllianzGI Global Water A \\
\hline PIO & Global Water ETF & AWTAX & AllianzGI Global Water A \\
\hline TAN & Solar ETF & HEOMX & Hartford Environmental Opportunities A \\
\hline ETHO & ETHO Climate Leadership ES ETF & FSLEX & Fidelity Select Envir and Alt Engy Port \\
\hline PZD & Invesco Cleantech ETF & AWTAX & AllianzGI Global Water A \\
\hline GRID & $\begin{array}{l}\text { NASDAQ Clean Edge } \\
\text { Infrastructure Index Fund }\end{array}$ & HEOMX & Hartford Environmental Opportunities A \\
\hline GEX & Vectors Global Alternative Energy & ALTEX & Firsthand Alternative Energy \\
\hline \multicolumn{4}{|c|}{ Social Funds } \\
\hline SHE & SPDR SSGA Gender Diversity ETF & GWILX & Glenmede Women in Leadership US Eq \\
\hline CATH & S\&P 500 Catholic Values ETF & AQEIX & LKCM Aquinas Catholic Equity \\
\hline EQLT & Workplace Equality ETF & TICHX & TIAA-CREF Social Choice Eq Advisor \\
\hline BIBL & Inspire $100 \mathrm{ETF}$ & AQEIX & LKCM Aquinas Catholic Equity \\
\hline BLES & Inspire Global Hope ETF & VCSOX & VALIC Company 1 Global Social Awareness \\
\hline
\end{tabular}

\subsection{Summary Statistics}

With our ETFs and mutual funds identified, we gathered key data, including total AUM, sustainability (i.e., ESG) score, the fund's inception date, the category of the fund (equity or bond), the sub-category (if the fund primarily invested in international holdings, domestic holdings, or a combination), a reported expense ratio for the ETF, daily trading volume, and both one- and two-year historical returns (the latter of which is the longest time available to create a usable sample size).

We examine the period July 1, 2016 through June 30, 2018. Using the data collected, we calculate typical risk and return metrics such as beta, alpha, and Sharpe ratio. In addition, we specifically calculate the difference in metrics between the ESG-focused ETFs and their matched actively managed mutual funds. See Table 2 for a detailed list and description of each metric and Table 3 for basic summary statistics across the entire sample.

Table 2. Definitions

\begin{tabular}{|l|l|}
\hline Metric & Definition \\
\hline DiffRet & $\begin{array}{l}\text { The difference in average daily return between the passive ETF and its active counterpart. A positive value } \\
\text { is indicative of outperformance. }\end{array}$ \\
\hline DiffDev & $\begin{array}{l}\text { The difference in the standard deviation of the daily returns between the passive ETF and its active } \\
\text { counterpart. }\end{array}$ \\
\hline Beta & $\begin{array}{l}\text { A measure of systematic risk, which we calculate for the ETF relative to its matched mutual fund. A value } \\
\text { below 1 indicates the ETF has less systematic risk than its matched counterpart. }\end{array}$ \\
\hline Alpha & $\begin{array}{l}\text { Jensen's alpha, calculated by regressing daily returns of the passive ETF against the returns of its active } \\
\text { counterpart (i.e., the index). Alpha represents the intercept from this regression. A positive value is } \\
\text { indicative of ETF outperformance. }\end{array}$ \\
\hline DiffSharpe & $\begin{array}{l}\text { The difference between the Sharpe ratio of the passive ETF and its active counterpart. The Sharpe ratio is } \\
\text { calculated as average return divided by standard deviation. A positive value is indicative of } \\
\text { outperformance. }\end{array}$ \\
\hline DiffTreynor & $\begin{array}{l}\text { The difference between the Treynor ratio of the passive ETF and its active counterpart. The Treynor ratio } \\
\text { is calculated as average return divided by the fund's beta. A positive value is indicative of outperformance. }\end{array}$ \\
\hline
\end{tabular}

Table 3. Summary Statistics Full Sample

\begin{tabular}{llll}
\hline & Mean & Std. Dev. & $\boldsymbol{t}$-stat \\
\hline ExpDiff & $-0.64 \%$ & $0.44 \%$ & $-7.59 * * *$ \\
Volume & 22,480 & 40,151 & $2.96 * * *$ \\
Diff1yRet & $0.00 \%$ & $0.00 \%$ & 1.15 \\
Diff2yRet & $0.00 \%$ & $0.00 \%$ & -0.00 \\
Diff1yDev & $0.00 \%$ & $0.00 \%$ & $3.36 * * *$ \\
Diff2yDev & $0.01 \%$ & $0.03 \%$ & 1.19 \\
Beta1y & 0.83 & 0.26 & $16.58 * * *$ \\
Beta2y & 0.88 & 0.23 & $16.72 * * *$
\end{tabular}




$\begin{array}{llll}\text { Alpha1y } & 0.00 \% & 0.00 \% & 1.60 \\ \text { Alpha2y } & 0.00 \% & 0.00 \% & 1.48 \\ \text { Diff1ySharpe } & 0.00 & 0.05 & 0.26 \\ \text { Diff2ySharpe } & 0.00 & 0.04 & 0.44 \\ \text { Diff1yTreynor } & 0.02 & 0.10 & 1.65 \\ \text { Diff2yTreynor } & 0.00 & 0.07 & 0.28\end{array}$

Note: ExpDiff is the difference in expense ratio between the ETF and mutual fund, and Volume is average daily trading volume of the ETF. All other variables are as previously defined. For observations involving one year, $\mathrm{n}=28$; and for two years, $\mathrm{n}=19$. $t$-statistics are for a simple test of the mean being different from zero. *indicates significance of at least the $10 \%$ level; **indicates significance of at least the $5 \%$ level; $* * *$ indicates significance of at least the $1 \%$ level

The first column in Table 3 reports the mean for each variable (by time period: 1-year or 2-year, where applicable); the second column provides the standard deviations; and the final column provides the results of a simple t-test of the mean being different from zero. Consistent with our expectations, the average expense ratio for our sample of ETFs is, on average, 0.64 percent lower as compared to the matched sample of mutual funds. Based on previous research, we would expect the return difference to be positive, particularly given the lower expense ratio for the ETFs. However, we find no difference in returns, which may suggest some tangential benefit from active management - i.e., we infer that the cost advantage of the ETF is essentially offset by the benefit of active management within the constrained SRI framework.

Recall for Beta and Alpha that we calculate the metrics by comparing the returns of the ETF to the return of the matched mutual fund. Thus, a beta below 1 indicates that, on average, the ETFs have lower relative risk. While the alpha is significantly positive, the values are so small as to be economically irrelevant. For the Sharpe and Treynor ratios, we find that the ETFs generally have similar risk-adjusted performance. Taken as a whole, we can initially conclude that ETFs, as expected, have lower expense ratios, but performance is insignificantly different. Thus, in contrast to most other areas, it seems that passive investing, in the aggregate, is just as good as active, but not much better. So, a socially responsible investor could likely follow either approach and generate a similar return outcome.

\section{Results}

\subsection{Segmented by Characteristic}

Since environmental funds make up roughly half of the ETFs in our sample, we segmented our data and evaluated environmental funds against the rest of the sample. We report the results of this analysis in Table 4. Recall that we limit our sample to funds with two-year returns available. Much of this is due to data availability, but it is partially a function of the fact that environmental funds are generally older, so any focus on three-year data would have resulted in the sample being almost exclusively environmental funds.

We find that environmental funds, on average, have a significantly higher expense ratio. We also find that environmental funds, on average, tend to have a higher beta. Across the other variables, we found no differences in performance metrics of environmental versus non-environmental funds.

Table 4. Statistics Segmented by Environmental

\begin{tabular}{llll} 
& Non-Environmental & Environmental & $\begin{array}{l}\text { Diff test } \\
\text {-stat }\end{array}$ \\
\hline Environmental & $50 \%$ & $50 \%$ & $-2.52 * *$ \\
Expense & $0.38 \%$ & $0.55 \%$ & -1.26 \\
Volume & 13,023 & 31,933 & -0.97 \\
Diff1yRet & $0.00 \%$ & $0.00 \%$ & -1.24 \\
Diff2yRet & $-0.00 \%$ & $0.00 \%$ & -0.98 \\
Diff1yDev & $0.00 \%$ & $0.00 \%$ & -1.17 \\
Diff2yDev & $0.00 \%$ & $0.01 \%$ & $-2.94 * *$ \\
Beta1y & 0.70 & 0.96 & -1.45 \\
Beta2y & 0.71 & 0.95 & -1.13 \\
Alpha1y & $0.00 \%$ & $0.00 \%$ & 1.27 \\
Alpha2y & $0.00 \%$ & $0.00 \%$ & -0.91 \\
Diff1ySharpe & -0.01 & 0.01 & -1.18 \\
Diff2ySharpe & -0.01 & 0.01 & 1.48 \\
Diff1yTreynor & 0.06 & 0.00 & 0.62 \\
Diff2yTreynor & 0.02 & 0.00 & \\
\hline
\end{tabular}


Note: All variables are as previously defined. For observations involving one year, $\mathrm{n}=14$ for both; and for two years, $\mathrm{n}=14$ for environmental and $\mathrm{n}=5$ for non-environmental. $t$-statistics are from a difference test of the means for environmental and non-environmental ETFs. When the p-value is greater than 0.05 , the pooled (equal variance) $t$-value is reported. When the p-value is less than 0.05 the Satterthwaite (unequal variance) $t$-value is reported. *indicates significance of at least the $10 \%$ level; **indicates significance of at least the $5 \%$ level; ***indicates significance of at least the $1 \%$ level

Since various studies (Hanouna, Agarwal \& Moussawi, 2017) have found that increased trading volume can impact fund performance and liquidity, as well as reduce trading costs, we examine this possibility by segmenting our sample based on trading volume at or below median (Low Volume) and those funds with above median trading volume (High Volume). We report these results in Table 5. We find that environmental funds, on average, have higher trading volume, likely due to their older age. We also find that higher volume funds have larger betas, but this is likely due to the overlapping influence of the environmental funds. We will control for this in the multivariate analysis in the next section. Otherwise, we did not find any performance metrics that were significantly different between the two samples.

Table 5. Statistics Segmented by Volume

\begin{tabular}{|c|c|c|c|}
\hline & Low Volume & High Volume & $\begin{array}{l}\text { Diff test } \\
t \text {-stat }\end{array}$ \\
\hline Environmental & $29 \%$ & $71 \%$ & $-2.42 * *$ \\
\hline Expense & $0.45 \%$ & $0.47 \%$ & -0.34 \\
\hline Volume & 3,175 & 41,784 & $-2.86^{* * *}$ \\
\hline Diff1yRet & $0.00 \%$ & $0.00 \%$ & -0.49 \\
\hline Diff $2 y$ Ret & $-0.00 \%$ & $0.00 \%$ & -0.00 \\
\hline Diff1yDev & $0.00 \%$ & $0.00 \%$ & -0.86 \\
\hline Diff2yDev & $0.00 \%$ & $0.01 \%$ & -1.09 \\
\hline Betaly & 0.66 & 1.00 & $-4.37 * * *$ \\
\hline Beta2y & 0.71 & 0.98 & $-2.27 *$ \\
\hline Alpha1y & $0.00 \%$ & $0.00 \%$ & -0.94 \\
\hline Alpha2y & $0.00 \%$ & $0.00 \%$ & 0.53 \\
\hline Diff1ySharpe & 0.01 & -0.00 & 0.51 \\
\hline Diff2ySharpe & 0.02 & -0.00 & 0.67 \\
\hline Diff1yTreynor & 0.05 & 0.01 & 1.06 \\
\hline Diff2yTreynor & 0.02 & -0.00 & 0.96 \\
\hline
\end{tabular}

Note: All variables are as previously defined. For observations involving one year, $\mathrm{n}=14$ for both; and for two years, $\mathrm{n}=7$ for low volume and $\mathrm{n}=12$ for high volume. $t$-statistics are from a difference test of the means for ESG ETFs with high volume and low volume. When the p-value is greater than 0.05 the pooled (equal variance) $\mathrm{t}$-value is reported. When the p-value is less than 0.05 the Satterthwaite (unequal variance) t-value is reported. *indicates significance of at least the $10 \%$ level; **indicates significance of at least the $5 \%$ level; ***indicates significance of at least the $1 \%$ level

Prior research (Nanigian, 2016) documents the negative impact that expenses have on performance. Therefore, we control for this potential impact by segmenting our sample by those at or below the median expense ratio (Low Expense) and those with an above median expense ratio (High Expense). We report these results in Table 6. Similar to above, we find that environmental funds make up the majority of the high expense category. Thus, any differences may be skewed. With that in mind, we find that high expense funds have a higher beta in each time period examined. Across the other metrics, we find little difference. 
Table 6. Statistics Segmented by Expense

\begin{tabular}{llll}
\hline & Low Expense & High Expense & $\begin{array}{l}\text { Diff test } \\
\boldsymbol{t} \text {-stat }\end{array}$ \\
\hline Environmental & $20 \%$ & $85 \%$ & $-4.30^{* * *}$ \\
Expense & $0.31 \%$ & $0.64 \%$ & $-8.52^{* * *}$ \\
Volume & 13,788 & 32,509 & -1.17 \\
Diff1yRet & $0.00 \%$ & $0.00 \%$ & -0.84 \\
Diff2yRet & $-0.00 \%$ & $0.00 \%$ & -1.51 \\
DiffyDev & $0.00 \%$ & $0.00 \%$ & $-2.46^{*}$ \\
Diff2yDev & $0.00 \%$ & $0.01 \%$ & -1.19 \\
Beta1y & 0.74 & 0.93 & $-2.16^{* *}$ \\
Beta2y & 0.76 & 0.95 & $-1.94 *$ \\
Alpha1y & $0.00 \%$ & $0.00 \%$ & 0.77 \\
Alpha2y & $0.00 \%$ & $0.00 \%$ & 1.08 \\
Diff1ySharpe & -0.00 & 0.01 & -0.52 \\
Diff2ySharpe & -0.01 & 0.01 & -0.93 \\
Diff1yTreynor & 0.05 & 0.01 & 1.36 \\
Diff2yTreynor & 0.01 & 0.00 & 0.47 \\
\hline
\end{tabular}

Note: All variables are as previously defined. For observations involving one year, $\mathrm{n}=15$ for low expense and $\mathrm{n}=13$ for high expense; For observations for two years, $\mathrm{n}=7$ for low expense and $\mathrm{n}=12$ for high expense. $t$-statistics are from a difference test of the means for ESG ETFs with high expense ratios and low expense ratios. When the p-value is greater than 0.05 the pooled (equal variance) t-value is reported. When the p-value is less than 0.05 the Satterthwaite (unequal variance) $t$-value is reported. *indicates significance of at least the $10 \%$ level; **indicates significance of at least the $5 \%$ level; ***indicates significance of at least the $1 \%$ level

\subsection{Regression Results}

To control for the potentially overlapping influences identified above, we turn to a multiple regression framework. In particular, we run a series of regressions where the dependent variable is each of the respective performance variable (DifflyRet, Alphaly, etc.). The independent variables are binary variables that represent whether a particular ETF is environmental (1) or not (0); low (0) or high (1) expense; and low (0) or high (1) volume. The model is as follows:

$$
\text { Dep }_{\mathrm{i}}=\alpha+\beta_{1} \text { Environmental }+\beta_{2} \text { HighExpense }+\beta_{3} \text { HighVolume }+\varepsilon_{\mathrm{I}}
$$

We report the results of these regressions in the various panels in Table 7. Each column represents the results of a different regression, with coefficient estimates (and associated $t$-statistics) reported.

Across the regressions, the most notable finding is the lack of any consistent significance. When controlling for all the factors, the only significant findings are that high expense funds have higher deviations and lower (1-year) alphas, and that higher volume funds have higher betas. With regard to all other areas, the results are insignificant, suggesting little difference between using ETFs and actively managed funds to invest based on an SRI philosophy. As a robustness test, we replaced the high expense independent variable with an expense difference variable, which was calculated as the expense ratio of the ETF subtracted from the expense ratio of its matched ESG mutual fund. Further, we also examined tracking error and the information ratio as additional measures of performance. In all cases, our results remained robust.

\section{Table 7. Regressions}

Panel A: Return Differences Regressions

\begin{tabular}{lll}
\hline & Diff1yRet & Diff2yRet \\
\hline Intercept & -0.00 & -0.00 \\
& $(-0.72)$ & $(-1.09)$ \\
Environmental & 0.00 & 0.00 \\
& $(0.38)$ & $(0.45)$ \\
& & \\
HighExpense & 0.00 & 0.00 \\
& $(0.70)$ & $(1.19)$ \\
HighVolume & 0.00 & -0.00 \\
& $(0.40)$ & $(-0.28)$ \\
$\mathrm{n}$ & 19 & 19 \\
Adj. $\mathrm{R}^{2}$ & -.0804 & .0032 \\
\hline
\end{tabular}


Panel B: Standard Deviation Differences Regressions

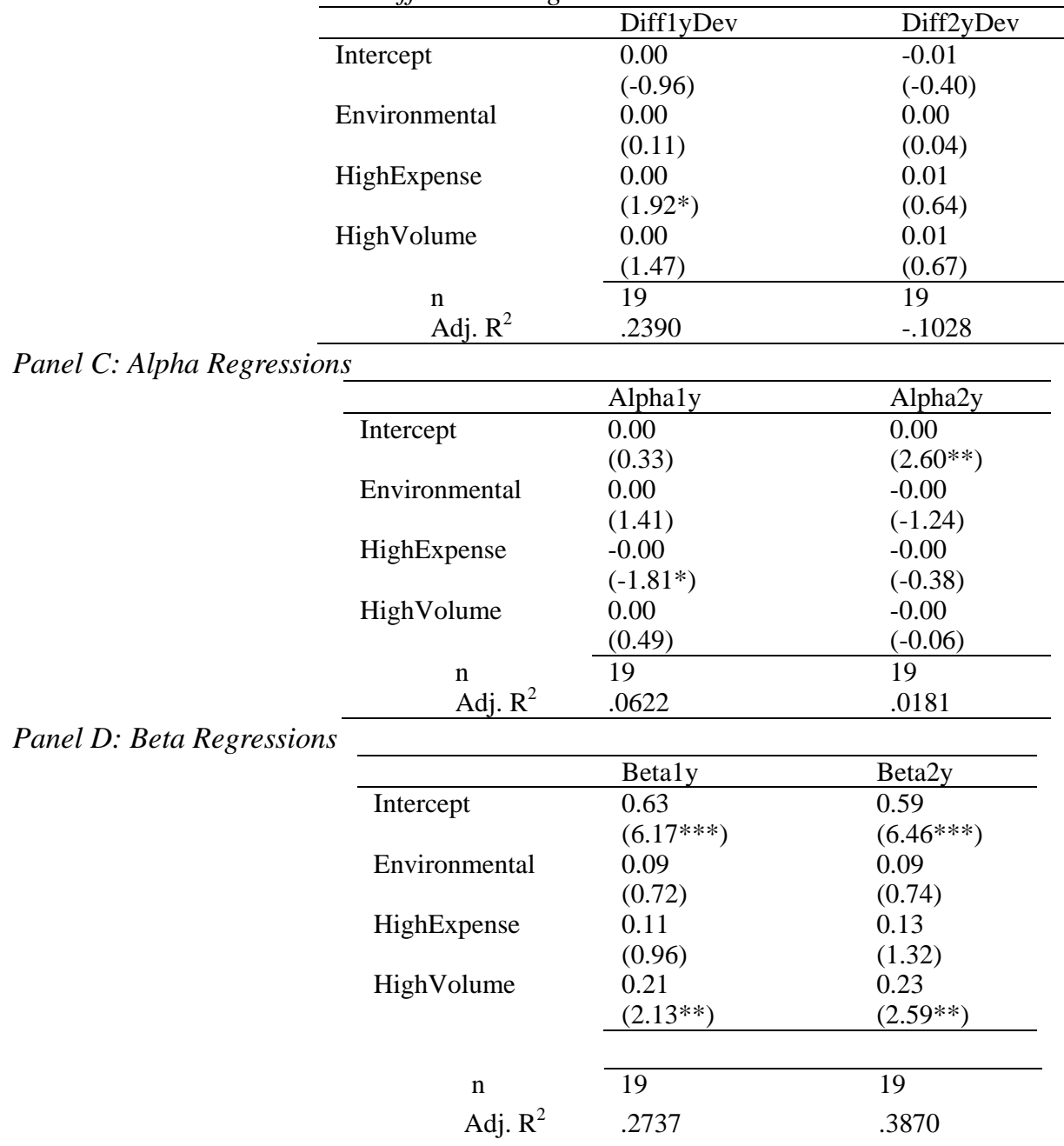

Panel E: Sharpe Ratio Regressions

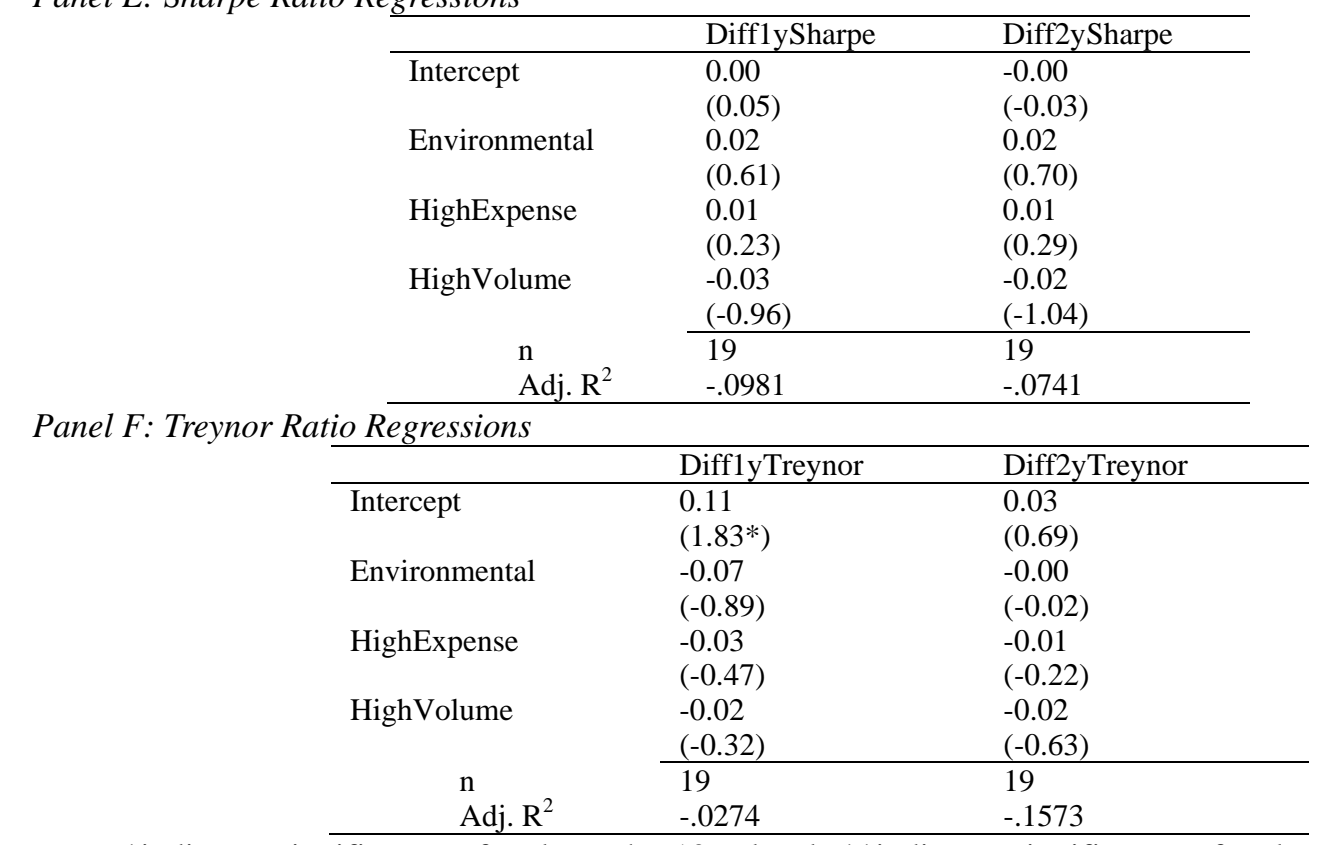

Note: *indicates significance of at least the $10 \%$ level; **indicates significance of at least the $5 \%$ level; and $* * *$ indicates significance of at least the $1 \%$ level 


\section{Conclusion}

SRI is becoming a mainstream part of the investment world, particularly for younger investors. The number of funds is quickly growing, both on the active and passive side. With the debate surrounding which approach is more effective, it is important for investors to determine how best to implement this strategy. What we know from prior research can be summarized in two key points. First, SRI investors do not sacrifice performance relative to more traditional, unconstrained investment strategies. Second, passively managed investments tend to outperform active investments.

What we didn't know, at least prior to this research, is whether social investors could implement their SRI constraints within a passive framework. To examine this issue, we examine a set of 28 ESG-focused ETFs and compare them to a matched sample of ESG actively managed mutual funds. While this is a small set, it is the largest we could create based on the newness of this area and the relative lack of supporting data. We find that the passive ETFs, as expected, have a lower expense ratio; however, they have about the same performance metrics as their active counterparts. These findings seem to imply two key takeaways. First, social investors appear to have the same choice as more traditional investors - i.e., they are able to choose either low-cost ETFs or active management to employ their investment strategy. Second, however, the typical outperformance we see with passive management is non-existent. Thus, employing SRI practices does seem to benefit from some degree of active management. Taken together, our findings suggest that SRI investors could follow either an active or passive approach and expect to earn similar risk-adjusted returns, with the apparent cost advantage of the ETFs offsetting the active benefit within the SRI investment structure.

Although we believe this study makes a significant contribution, we readily admit that the small sample size and return history suggest taking any results with caution. Moving forward, we encourage researchers to revisit this area as more funds and a longer time horizon are available, particularly examining the returns in a time-series (e.g., Fama \& French, 1993) framework.

\section{References}

Amel-Zaded, A., \& Serafeim, G. (2018). Why and how investors use ESG information: Evidence from a global survey. Financial Analysts Journal, 74(3), 87-103. https://doi.org/10.2469/faj.v74.n3.2

Bowen, H. R. (1953). Social Responsibilities of the Businessmen. New York, NY: Harper.

Clark, G. L., \& Viehs, M. (2014). The implications of corporate social responsibility for investors: An overview and Evaluation of the Existing CSR Literature. SSRN Electronic Journal. https://doi.org/10.2139/ssrn.2481877

Dolvin, S., Fulkerson, J., \& Krukover, A. (2019). Do "good guys" finish last? The relationship between morningstar sustainability ratings and mutual fund performance. Journal of Investing, 28(2), 77-91.

Epstein, E. M. (1989). Business ethics, corporate good citizenship and the corporate social policy process: A view from the United States. Journal of Business Ethics, 8(8), 583-595. https://doi.org/10.1007/BF00383027

Fama, E., \& French, K. (1993). Common risk factors in returns on stocks and bonds. Journal of Financial Economics, 33(1), 3-56. https://doi.org/10.1016/0304-405X(93)90023-5

Freeman, R., \& Mcvea, J. (2000). A Stakeholder Approach to Strategic Management. SSRN Electronic Journal. https://doi.org/10.2139/ssrn.263511

Friede, G., Busch, T., \& Bassen, A. (2015). ESG and financial performance: aggregated evidence from more than 2000 empirical studies. Journal of Sustainable Investment, 5(4), 210-233. https://doi.org/10.1080/20430795.2015.1118917

Friedman, F. (1970, September 13). A Friednzan Doctrine. The New York Times.

Fulton, M., Kahn, B., \& Sharples, C. (2013). Sustainable investing: Establishing long-term value and performance. Deutsche Bank Group. SSRN Electronic Journal. https://doi.org/10.2139/ssrn.2222740

Ghoul, S., Guedhami, O., Kwok, C., \& Mishra, D. (2011). Does corporate social responsibility affect the cost of capital? Journal of Banking \& Finance, 35(9), 2388-2406. https://doi.org/10.1016/j.jbankfin.2011.02.007

Goss, A., \& Roberts, G. S. (2011). The impact of corporate social responsibility on the cost of bank loans. Journal of Banking \& Finance, 35(7), 1794-1810. https://doi.org/10.1016/j.jbankfin.2010.12.002

Governance \& Accountability Institute. (2018). FLASH REPORT: 85\% of S\&P 500 Index Companies Publish Sustainability Reports in 2017. Governance \& Accountability Institute, Inc. Retrieved from 
https://www.ga-institute.com/press-releases/article/flash-report-85-of-sp-500-indexR-companies-publis h-sustainability-reports-in-2017.html

Hanouna, P., Agarwal, V., \& Moussawi, R. (2017). Investigating the correlation between ETFs and their underlying securities. ETF Research Academy. Retrieved from

https://www.lyxoretf.co.uk/pdfDocuments/2.\%20DTP113198\%20- \%20Lyxor\%20ETF\%20Research\%2 0Academy\%20-\%20Expert\%20Opinion\%20Liquidity\%20EO\%20-\%20160617\%20(3)_ae366d54c9326 e906fc9f69f1c605e02.pdf

ICI Global. (2018). Worldwide Mutual Fund Market. Investment Company Institute. Retrieved from https://www.ici.org/research/stats

JP Morgan. (2018). Sustainable investing is moving mainstream. JP Morgan. Retrieved from https://www.jpmorgan.com/global/research/esg

KPMG. (2017). The KPMG survey of corporate responsibility reporting 2017. KPMG. Retrieved from https://home.kpmg/be/en/home/insights/2017/10/the-kpmg-survey-of-corporate-responsibility-reporting $-2017 . \mathrm{html}$

Morgan, S. (2015). Sustainable reality: Understanding the performance of sustainable investment strategies. Morgan Stanley Institute for Sustainable Investing. Retrieved from https://www.morganstanley.com/content/dam/msdotcom/ideas/sustainable-investing-offers-financial-per formance-lowered-risk/Sustainable_Reality_Analyzing_Risk_and_Returns_of_Sustainable_Funds.pdf

Munoz-Torres, M. J., Fernandez-Izquierdo, M. A., \& Balaguer-Franch, M. R. (2004). The social responsibility performance of ethical and solidarity funds: An approach to the case of Spain. Business Ethics A European Review, 13(2-3). https://doi.org/10.1111/j.1467-8608.2004.00363.x

Nanigian, D. (2016). The expense-performance relationship (or lack thereof). Journal of Financial Planning, 29(3), 30-32.

O’Brien, A., Liao, L., \& Campagna, J. (2017). Responsible Investing: Delivering competitive performance. Nuveen TIAA Investments. Retrieved from https://www.nuveen.com/en-us/thinking/responsible-investing/responsible-investing-delivering-competi tive-performance

Orlitzky, M., Schmidt, F. L., \& Rynes, S. L. (2003). Corporate social and financial performance: A meta-analysis. Organization Studies, 24(3), 403-440. https://doi.org/10.1177/0170840603024003910

Petruno, T. (2017, April 9). Small investors' move to 'passive' stock funds become a stampede. Los Angeles Times.

Prondzinski, D. (2010). Passive versus active management of mutual funds: Evidence from the 1995-2008 period. Retrieved from https://nsuworks.nova.edu/hsbe_etd/94/

Schueth, S. (2003). Socially responsible investing in the United States. Journal of Business Ethics, 43(3), 189-194. https://doi.org/10.1023/A:1022981828869

Stein, C. (2018). Shift from active to passive approaches tipping point. Bloomberg. Retrieved from https://www.bloomberg.com/news/articles/2018-12-31/shift-from-active-to-passive-approaches-tippingpoint-in-2019

Townsend, B. (2017). From SRI to ESG: The origins of socially responsible and sustainable investing. Bailard Wealth Management. Retrieved from https://www.bailard.com/wp-content/uploads/2017/06/Socially-Responsible-Investing-History-BailardWhite-Paper-FNL.pdf?pdf=SRI-Investing-History-White-Paper

USSIF. (2017). SRI basics. The Forum for Sustainable and Responsible Investment. Retrieved from https://www.ussif.org/sribasics

USSIF. (2018). USSIF Trends Report. The Forum for Sustainable and Responsible Investment. Retrieved from https://www.ussif.org/files/Trends/Trends\%202018\%20executive\%20summary\%20FINAL.pdf

Wirz, M. (2018, June 19). Social investing has a new message. The Wall Street Journal.

\section{Copyrights}

Copyright for this article is retained by the author(s), with first publication rights granted to the journal.

This is an open-access article distributed under the terms and conditions of the Creative Commons Attribution license (http://creativecommons.org/licenses/by/4.0/). 